\title{
REVERSAL OF NEUROMUSCULAR BLOCKADE BY ARTIFICIAL DIURESIS: CASE REPORT
}

\author{
J.S. ANAND, M.D., D.A. (BOM), R.K. MEHTA, M.B., B.S., D.A. (BOM), \\ C.A. MUNSH, M.B., B.S., D.A., AND D.H. MULLA, M.B., B.S., D.A. (BOM) ${ }^{\circ}$
}

\begin{abstract}
Gallamine tareizrodide (Flaxedil ${ }^{\text {}}$ ) has been used as a neuromuscular blocking agent in anaesthetic practice since 1948. Despite wide variations reported by many workers, it is accepted beyond doubt that the duration of action of gallamine is largely determined by the renal excretion of the drug and that it is largely excreted unchanged in the urine. Reports of prolonged paralysis following the administration of gallamine to patients with renal failure have justified this assumption.

We present a case report of a man who underwent vagotomy and gastrojejunostomy in the course of which he was given by accident the unusually high dose of $400 \mathrm{mgm}$ of gallamine triethiodide. Because of hypovolaemia and poor urinary output the neuromuscular block persisted in spite of reversal with atropine and prostigmine. However, the block was reversed effectively by artificial diuresis preceded by the rapid intravenous infusion of fluid.
\end{abstract}

\section{Case Refort}

A 30-year-old man was brought to the operating room for vagotomy and gastrojejunostomy, On the morning of the operation he was premedicated with atropine $0.6 \mathrm{mgm}$, meperidine $50 \mathrm{mgm}$, and promethazine $25 \mathrm{mgm}$ given intramuscularly'. Anaesthesia was induced with intravenous sodium thiopentone $300 \mathrm{mgm}$ and succinylcholine $100 \mathrm{mgm}$. The lanyx was sprayed with lidocaine 4 per cent (Xylocaine $e^{8}$ and oral tracheal intubation accomplished with a No. 9 Magill's cuffed tube. After recovery from the effect of succinylcholine, anaesthesia was maintained with nitrous oxide, oxygen (70:30) in a closed circuit and $400 \mathrm{mgm}$ gallamine triethiodide was given. Arterial blood pressure and pulse remained within normal limits throughout the operation, which lasted for over 2 hours. During this period $1000 \mathrm{ml}$ of 5 per cent glucose was given by intravenous drip infusion. Blood transfusion was not necessary as there was hardly any blood loss. Postoperatively, spontaneous respiration returned but the ventilation was grossly inadequate. At this stage neostigmine $2.5 \mathrm{mgm}$ with atropine $1.2 \mathrm{mgm}$ was given intravenously but without any obvious recovery from the block. In view of the inadequate respiratory exchange we decided to continue ventilation to allow the neuromuscular block to wear off naturally without further anticholinesterase therapy. Peripheral nerve stimulation confirmed persistence of a non-depolarizing type of block.

-Department of Anaesthesia, B.Y.L. Nair Charitable Hospital and Topiwala National Medical College, Bombay 8. 
After one hour there was still no sign of recovery and therefore he was given further atropine $0.6 \mathrm{mgm}$ followed by $2 \mathrm{mgm}$ of prostigmine. but again without improvement. The cardiovascular status had been stable throughout the operative and post-operative periods.

At this stage the patient's urinary bladder was catheterized and it was found that in a period of $4 \%$ hours he had secreted hardly $35 \mathrm{ml}$ of urine. Central Venous Pressure was $3 \mathrm{~cm} \mathrm{H}_{2} \mathrm{O}$. Three litres of lactated Ringer's solution and $1000 \mathrm{ml}$ of 5 per cent glucose was infused intravenously to correct possible hypovolaemia. This was followed by a rapid drip infusion of $200 \mathrm{ml}$ of 20 per cent mannitol. Within 20 minutes of administration of mannitol the patient passed about $1200 \mathrm{ml}$ of urine and had a dramatic improvement in the muscle tone. No further paralysis was observed. He was transferred to the Recovery Room for further observation, but the subsequent course was uneventful.

\section{DIsCUISSION}

In the past, a few isolated cases have been reported suggesting a relation between poor renal function and a persistent effect of gallamine. The results of clinical studies by various authors suggest that there is a definite relationship between the duration of aetion of this drug and renal excretion. This does not appear to be the case with d-tubocurarine.

It has been shown in dogs that gallamine is excreted entirely by the kidneys. In the absence of renal function a sustained level of gallamine was obtained. ChurchillDavidson ${ }^{2}$ quotes a case in which a boy was mistakenly given $380 \mathrm{mgm}$ of gallamine during a kidney transplant and remained apnoeic for three days. The condition of that patient improved after dialysis.

A similar case has been reported recently by Lowenstein ${ }^{1}$ where neuromuscular block was overcome by peritoneal dialysis. This case established the value of artificial diuresis in the treatment of prolonged apnoea or paralysis following the intravenous administration of gallamine triethiodide.

Since gallanine is excreted largely in the urine, care should be taken to avoid conditions such as dehydration and hypotension, which can decrease urinary output. The possible reason for hypovalaemia in our case was preoperative starvation and extra fluid loss due to a tropical climate.

\section{SUMmaRY}

These findings suggest that the residual neuromuscular block due to administration of gallamine to a patient with poor renal excretion may be effectively overcome by artificial diuresis.

\section{ACKNOWLEDGMENT}

I am grateful to the Dean, B.Y.L. Nair Charitable Hospital and Topiwala National Medical College, for allowing us to publish this article. My thanks are due 
ANAND, et al.: REVERSAL OF NEUROMUSCULAR GIOCKADE.

to The Research Society of T.N. Medical College for providing the typing assistance.

\section{REFERENCES}

1. Lowenstenn, E, GoldFine, C., \& Flack, E. Anesthesiology 33: 556 (September, 1970)

2. Churchill-Davmson, H.C., Way, W.L., \& Dejono, R.H. The muscle relaxants and renal excretion. Anesthesiology 28:540 (May-June, 1967). 